\title{
The Effects of Auditory Training by Erber Method on Improvement of the Auditory Skills in 3-4 Year-Old Hearing-Impaired Children
}

\author{
Farnoush Jarollahi $^{* 1}$, Afsaneh Alinejad Kashani ${ }^{2}$, MohammadReza Keyhani ${ }^{3}$, Atefeh Kamalvand ${ }^{4}$
}

1. PhD in Audiology, Audiology Department, School of Rehabilitation Sciences, Iran University of Medical Sciences, Tehran, Iran

2. BS in Audioloy, Audiology Department, School of Rehabilitation Sciences, Iran University of Medical Sciences, Tehran, Iran

3. MSc in Statistics, Basic Sciences Department, School of Rehabilitation Sciences, Iran University of Medical Sciences, Tehran, Iran

4. MSc in Audiology, Audiology Department, University of Social Welfare and Rehabilitation Sciences, Tehran, Iran

\begin{tabular}{c} 
Article Info \\
\hline Received: $2018 / 10 / 09$ \\
Accepted: $2018 / 12 / 15$ \\
Published Online: $2018 / 12 / 30$ \\
DOI: $10.30699 /$ fdisj.1.3.36 \\
How to Cite This Article \\
Jarollahi F., Alinejad Kashani \\
A., Keyhani M., Kamalvand \\
A. The Effects of Auditory \\
Training by Erber Method on \\
Improvement of the Auditory \\
Skills in 3-4 Year-Old Hear- \\
ing-Impaired Children. \\
Function and Disability \\
Journal.2018 (Autumn). Vol \\
1. No: 4 Pages: 36-44. \\
\end{tabular}

Use your device to scan and read the article online

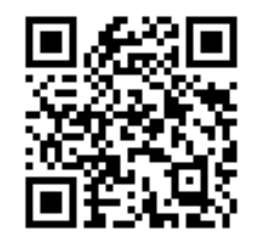

\section{ABSTRACT}

Background \& Objectives: Auditory sense is important for the learning of speech and language in childhood. Sensory-neural hearing loss can cause serious consequences in the development of auditory and communicational skills. Auditory training is of great importance in the aural rehabilitation services for decreasing these effects. Currently, there are several methods such as AVT, SKI-HI, DASL and also the Erber method. Given the specific characteristics of the Erber method, its benefit has not been shown in available researches yet. Therefore, this study aimed to apply Erber method to examine the improvement of auditory skills in sensorineural hearing-impaired children.

Methods: This clinical trial study was performed on 13 toddlers with severe-toprofound hearing loss. The Erber method was applied for auditory training. Exercises were performed over the first three months (only language therapy), and following that, auditory training was increased for six months. This 9-month period was repeated once. The assessments were repeated every three months by the "Tavana" test. The data of five repetitions of the Tavana test were analyzed by paired t-test.

Results: No significant difference was observed between the results from tests 1, 2 and 4, 5 tests. However, noticeable difference was observed between the results from the 2, 4 and 5, 7 tests. These findings revealed the auditory training by Erber method, which greatly improved the auditory skills.

Conclusion: Mere use of appropriate hearing-aid with language therapy without auditory training, would not lead to the improvement of auditory skills. Theseskills were rather improved by auditory training in hearing-impaired children. So, the Erber method was an appropriate and effective method for auditory training.

Keywords: Auditory Training, Hearing loss, Erber's method, Tavana test, Children

\section{Introduction}

People with normal hearing assume that if hearingimpaired children who apply assistive listening devices such as hearing-aid or cochlear implant, they can hear and understand speech sounds. This is an erroneous assumption concerning the sensory-neural hearing impairment. Sensory-neural hearing loss during childhood can cause serious damage to language comprehension, speech development, and the development of auditory and communicational skills; all of 
which can only be prevented with timely aural rehabilitation program (Jarollahi et al, 2010). According to Tye-Murray, audition is the major means of learning, especially learning of speech and language. So, the auditory skills training includes the development of the ability of hearing-impaired individuals in order to allow speech recognition by means of auditory stimuli and interpreting auditory experiences (Tye-Murray, 2009). Auditory training (AT) is of great importance in the aural rehabilitation services. The reason is that if properly and timely performed, it will not only increase the auditory skill level in the hearing-impaired child but will also have a positive and accelerating effect on other trainings such as speech and language therapies (Downs et al, 2002). They argued that the optimal acquiring of auditory skills is possible at certain times; called critical periods of the development of speech, language and hearing skills existing from birth to age 3 year old, and the learning period is considered to exist until the age of 5 years old (Downs et al, 2002). Other researchers have also noted that for providing early aural rehabilitation services, the early diagnosis of hearing impairment is significant. In addition, the children who receive rehabilitation interventions at an earlier age, show better auditory comprehensive, developmental, social, communicative, and expressive language functions than children who fail to receive these interventions at an earlier age (Roeser et al, 2000).

A study by Bloom in the 1980s conducted on 14 students within the age range of 14-16 with severe and profound hearing impairments in their hearing skills, revealed that the use of their residual hearing, even if hearing damage is at a high level of $110 \mathrm{~dB}$, can be very useful for understanding and producing speech but, the kind of method of AT was not mentioned. However, the success of AT programs for acquiring these abilities depends on access to well-trained teachers or therapists, appropriate listening devices, and the proper cooperation of the children (Bloom, 1980).

Tremblay examined the hearing system of nine adults with normal hearing while learning a new language

${ }^{1}$.Auditory Verbal Therapy

${ }^{2}$.Developmental Approach to Successful Listening by electrophysiological tests such as MMN. They concluded that auditory training in terms of behavior increases the ability of individuals to differentiate and identify the unfamiliar letters of the alphabet, and physiologically leads to an increased response duration in the MMN test and a reduction in the latency of the MMN wave. This study showed that the degree of central neurophysiologic priming as the basis of perceptual learning is altered by means of auditory training (Tremblay et al, 1997).

Up until now, numerous studies have been performed on the benefits of AT and its impact on the improvement of auditory skills (Tye-Murray, 2009) by different methods, as well as the role of factors affecting the improvement of auditory skills such as age (Jarollahi et al, 2010; Itano, 2000; Nicholas\&Geers, 2006), hearing loss (Erber, 1982; Blamy et al, 2001), parent awareness (Calderon, 2000; Sininger et al, 2010) and child motivation (Rohde, 1980). The findings of almost all these studies emphasize the importance of performing auditory education, especially in the earlier ages.

Besides the low age, the amount of hearing impairment is also effective on the outcome of AT and also on the selection of the appropriate method. Since the hearing loss with different degrees has different consequences on hearing-impaired children, it is necessary to consider the appropriate method for each child (TyeMurray, 2009). There are currently several methods; each having its own applications based on its characteristics, such as AVT $^{1}$ (14) and SKI-HI (Mc Namara et al, 1994) methods (home-based, informal exercises just with speech stimuli), DASL method ${ }^{2}$ (centerbased, formal exercises for four year-old children at 4 auditory skill levels)(16), and also Erber method (17) although is the older than these methods but it has various exercises at all auditory levels with speech and non-speech stimuli, can be done both formal and informal, both home- and center-based. The application of each method differs from the other (Tye-Murray, 2009; Manouchehri et al, 2011), but generally the Erber method is more flexible than the rest. 
Given the specific features of the Erber method (high flexibility, further adaptability for young children with different degrees of hearing impairment), the benefit of this method has not been discussed in available researches, hence, this study aims to apply the Erber method to examine the improvement of sound awareness, discrimination, recognition, and comprehension of speech in 3-4 year-old children who suffer severe to profound sensorineural hearing impairment.

\section{Materials and Methods}

\section{Participants}

Improvement of auditory skills was investigated in 13 children between 3 and 4 years with congenital severe and profound SNHL, who had no mental disability, no difficulty in vision and no problem in other peripheral and central nerves. They were selected by means of gradual (not random) sampling.

\section{Method and Procedure}

The method of the present study was clinical trial. The study approved by the Ethical Committee of Iran University of Medical Sciences (Ethics Committee Code: 369 ). The children were studied with the "Tavana" test (a valid auditory skills test for hearing impaired children between the ages 3-4: content validity $=94 \%$ and reliability $=99 \%$ ) (Jarollahi et al, 2010; Jarollahi, 1388) for 18 months as it is shown in figure 1. The "Tavana" test consists of four subtests and 34 subskills (first subtest: "sound detection" with ten subskills, second subtest: "sound discrimination" with ten subskills, third subtest: "sound identification" with 8 subskills, and fourth subtest: "speech comprehension" with six subskills). The "Tavana" test was first run for the children (Test 1), then they were trained with language therapy (LT), along with the use of hearing aids (HA) without AT for three months, and then the Tavana test was performed again (Test 2). In the next step, AT was added for 6 months to the previous educations and the improvement of children was assessed (tests 3 and 4). Once again, this 9-month period was repeated (tests 5, 6 and 7). Indeed, the reason for selecting this data collection method was due to the fact that AT is beneficial for hearing-impaired children, so, to take the ethical aspects of this study, we could not have the control group and we used self-control. The "Tavana" test was executed 7 times and the data were obtained by auditory skill level. A variable was analyzed with paired t-test, and by sex variable was analyzed with t-test. For these aims, the SPSS software version 17 was used.

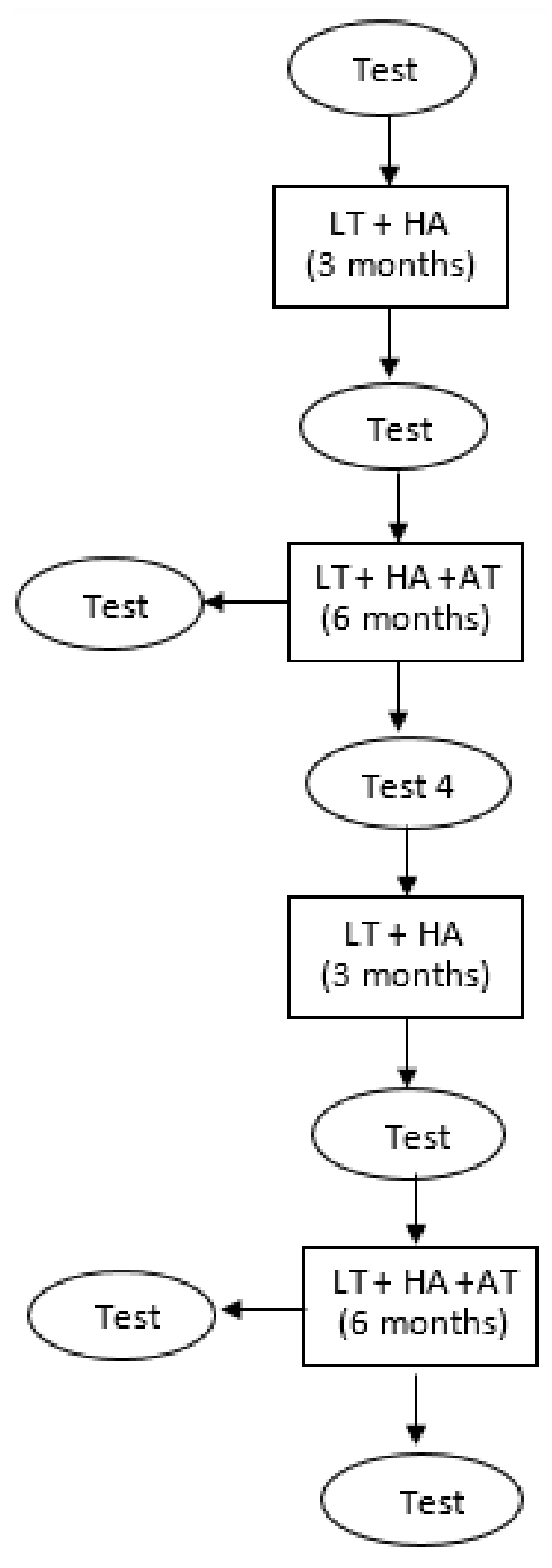

Figure 1. Diagram of the procedure 


\section{Results}

In this research, which investigated the effects of AT using the Erber method, data were collected on 13 children between the ages 3 and 4 (62\% female, mean age: 41.5 months \pm 5.01 , and $38 \%$ male, mean age: 38.6 months \pm 4.6 ). Demographic information divided by gender were shown in table 1 .

Table 1. Demographic information of hearing-impaired children $(n=13)$

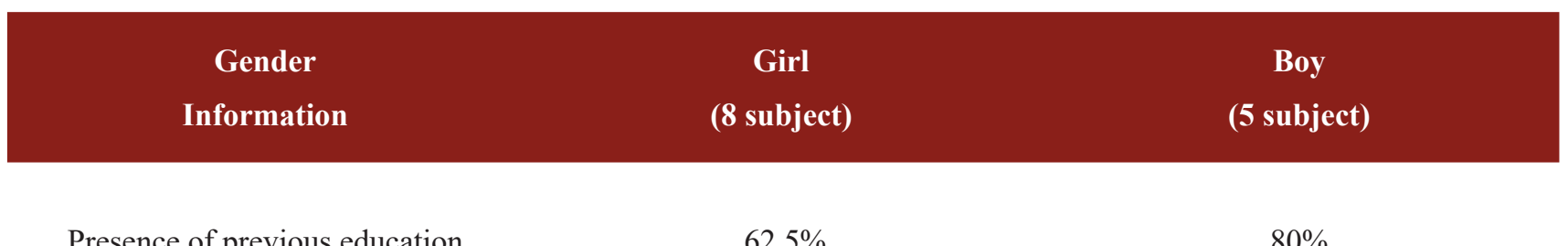
Presence of previous education
$62.5 \%$
$80 \%$

Mean age of suspect of HL

21.5 (months)

8.25 (months)
Mean age of definite of HL
28.75(months)
13.6 (months)

Mean age of covering HA

33(months)

24.6 (months)

Mean duration of using HA

Amount of HL without HA

Amount of HL with HA

Amount of HL with HA

Good parent participation
8.5 (months)

17.5 (months)

Profound: $75 \%$

Severe: $25 \%$

Moderate: $62.5 \%$

Mild:37.5\%

$62.5 \%$
Profound: $80 \%$

Severe: $20 \%$

Moderate: $60 \%$

Mild: $40 \%$

$80 \%$
The results of the Tavana test were analyzed at first, second, fourth, fifth and seventh evaluation stages. As it was expected, no significant difference was obtained between the tests 1 and 2, also between 4 and 5; as there was no AT education. On the other hand, it was anticipated that the significant difference was acquired between 2 and 4, also between 5 and 7, because AT was added to the previous educations.

\section{The Effect of AT on Sound Detection's Improve ment}

Paired t-test revealed no significant difference be- tween the scores obtained from the tests 1 and 2 $(P=0.297)$. However, there was a significant difference between the tests 2 and $4(P=0.006)$. There was no significant difference between the tests 4 and 5 , also between the tests 7 and 5, because the score of test 4 for the girls' group reached the maximum $(100 \%)$ and the score of the boys was lower than that of the girls, and this difference was close to the significant margin $(P=0.07)$. Also, there was a significant difference between the first and the last test $(P=0.017)$ (Table 2 and Figure 2). 
Table 2. Comparison of the mean scores and SD of four sub skills of Tavana test

\begin{tabular}{cccccc}
$\begin{array}{c}\text { Test repetition } \\
\text { sub skills }\end{array}$ & $\begin{array}{c}\mathbf{1}^{\text {st }} \text { test } \\
(\boldsymbol{\%} \pm \mathbf{S D})\end{array}$ & $\begin{array}{c}\mathbf{2}^{\text {nd }} \text { test } \\
(\boldsymbol{\%} \pm \mathbf{S D})\end{array}$ & $\mathbf{4}^{\text {th }}$ test & $\mathbf{5}^{\text {th }}$ test & $\mathbf{7}^{\text {th }}$ test \\
Sound Awareness & $58.85 \pm 38.03$ & $55.38 \pm 39.08$ & $84.62 \pm 29.90$ & $95.00 \pm 15.81$ & $95.00 \pm 15.81$ \\
Sound Discrimination & $37.7 \pm 39.67$ & $40.77 \pm 41.92$ & $73.46 \pm 36.19$ & $93.50 \pm 10.55$ & $99.00 \pm 3.16$ \\
\hline Sound Identification & $12.50 \pm 16.34$ & $12.02 \pm 20.96$ & $39.91 \pm 35.04$ & $42.51 \pm 36.19$ & $71.27 \pm 34.47$ \\
Speech Comprehension & $1.92 \pm 6.93$ & $2.54 \pm 9.15$ & $16.00 \pm 26.60$ & $20.84 \pm 34.98$ & $52.50 \pm 42.50$ \\
\hline Total & $42.502 \pm 22.39$ & $32.38 \pm 27.24$ & $58.79 \pm 28.01$ & $69.25 \pm 17.63$ & $83.37 \pm 17.97$ \\
\hline
\end{tabular}

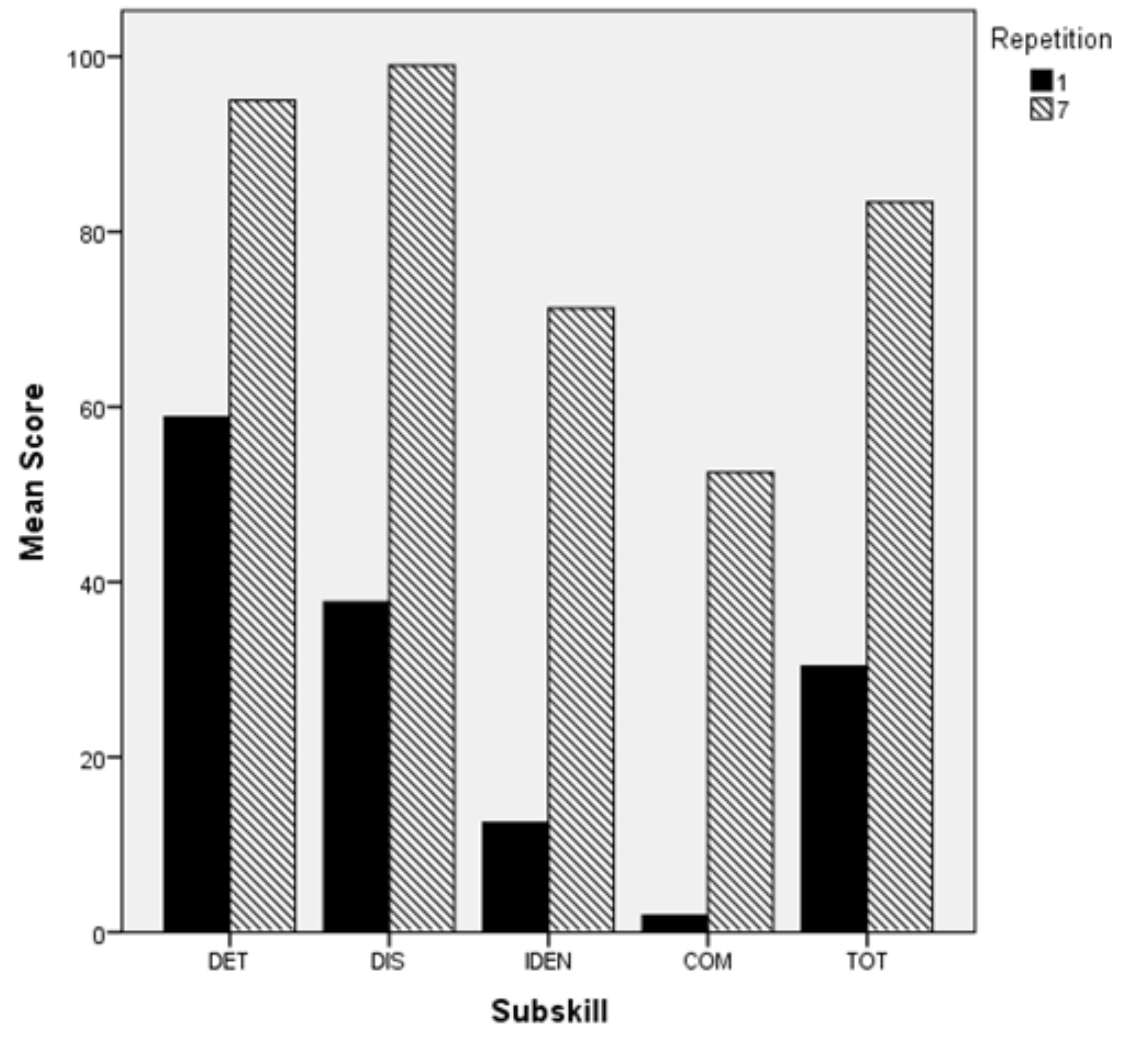

Figure 2. Comparison of Tavana test's scores at four sub skills and totally: DET=detection, DIS=discrimination, IDEN=identification, COM=comprehension, TOT=test totally, Repetition $1=1$ st test and Repetition $7=$ final test after 18 months.

The Effect of AT on Sound Discrimination's Improvement

Paired t-test showed no significant difference between the scores obtained from tests 1 and 2, also between 4 and 5 ( $P=0.165$ and $P=0.148$, respectively). There was a significant difference between the tests 2 and $4(P=0.005)$. However no significant difference was found between the tests 5 and $7(P=0.102)$. Also, there was a significant difference between the first and the final test $(P=0.002)$. The T-test showed no significant difference between the scores of girls and boys (Table 2 and Figure 2).

The Effect of AT on Sound Identification's Improvement

There was no significant difference between the scores obtained from the tests 1-2 and 4-5, in no auditory training was performed $(P=0.865, P=0.102$, respectively), but between tests 2-4 and 5-7 there was a significant difference $(P=0.003, P=0.004$, respectively), and consequently, there was a signifi- 
cant difference between the scores of the first and the last test, which indicates the effect of auditory training exercises on the improvement of sound recognition skills $(P=0.000)$. There was a significant difference between the scores of girls and boys and girls got higher points (Table 2 and Figure 2).

\section{The Effect of AT on Speech Comprehension's Im- provement}

There was no significant difference between the scores obtained from the tests 1-2 and 4-5, when AT was not performed $(P=0.337$ and $\mathrm{P}=0.804$, respectively), but significant differences were observed between the scores from tests 2 and 4, 5 and 7 also 1 and $7(P=0.036, P=0.009, P=0.003$, respectively). In this ability t-test, it was shown that girls also earned higher scores than boys, which was also significant (Table 2 and Figure 2).

Regardless of the kind of sub-test of the "Tavana" test, the study concentrated on children's auditory skills in general and there was no significant difference between the tests 1 and 2 also 4 and 5 (P-values were 0.491 and 0.706 , respectively), but between tests 2 and 4, 5 and 7 also 1 and 7 a significant difference ( $P=0.001, P=0.003, P=0.001$, respectively) was observed. Also in this case, girls gained higher points than the boys (Table 2 and Figure 2).

\section{Discussion}

The present study revealed the effects of AT by the Erber method on the development of the four auditory skills of detection, discrimination, recognition and comprehension with a controlled method. It showed that regardless of having appropriate HA and despite the presence of previous trainings in aural rehabilitation (such as speech and language therapy), AT, by increasing the scores in the "Tavana" test, leads to the all four auditory skills in the studied children, and there was a significant difference between the scores of the test-retests.

From among the auditory skills, the easiest and most basic auditory skill is sound detection and the most difficult auditory skill is the speech comprehension (Tye-Murray, 2009). In this study, at the detec- tion stage (seen as the simplest and relatively quick learned stage), the average score in all repeated tests, were the highest, i.e. it was maximum at mid-term (after six months) and therefore in the next tests, which were completed by the end of the 18-month training period, similar results were revealed. Therefore, the effects of AT on the improvement of sound detection was indicated and it was consistent with the previous researches (Hoekstra et al, 1999; Chanyagom et al, 2014; Beier et al, 2015).

Moreover, the score in the discrimination stage reached to maximum for the children during the first 9 months of training. Therefore, the results of the two last tests were similar and did not have a significant difference. So the effects of AT on the improvement of sound discrimination skill were shown and proved to be in agreement with the other researches carried out via different methods of AT (Chanyagom et al, 2014; Beier et al, 2015).

Sound recognition and comprehension skills which were harder than discrimination skills took longer to be trained (Tye-Murray, 2009). Consequently, at the end of the 18-month training program, while the scores had improved, they were still not completed. This indicated that training should be continued so that the sound recognition and comprehension could reach their ideal scores, and this data comes in agreement with other studies (Kricos, 2007; Henshaw \& Ferguson, 2015; Kavanagh, 2017).

In fact, this study revealed that the AT by Erber method improved all four levels of auditory skills in the hearing impaired children, and was an effective and flexible method for AT, especially for children with profound HL. In addition, this study confirmed the efficacy of AT just like other studies from previous researchers (Jarollahi et al, 2010; Rohde, 1980; Manouchehri, 2011; Hoekstra et al, 1999; Beier et al, 2015).

In this study (62\% girls), there was a difference between the scores obtained by girls and by boys at each auditory skill level. At the sound awareness stage, the boys' scores were lower than that of the girls', although not significantly $(P=0.07)$. There was no difference between the scores of the two groups of 
girls and boys in the stage of sound discrimination. In the stage of sound recognition, there was a significant difference between the scores of the two groups. Although, the girls' scores were higher than that of the boys $(P=0.04)$, and finally, in the comprehension stage, the girls' group gained higher scores than boys. The more the stage progressed, the difference in scores broadened $(P=0.02)$. James Hall has mentioned that males (whether adults or children) show slower, lower, shorter, and less sensitive responses than females of the same age. The most commonly used explanation for the functional differences is the impact of hormonal factors on neuronal transmission (Hall, 2000). However, further studies with more samples were needed.

\section{Conclusion}

The Erber method for auditory training had a great and effective impact and caused a noticeable improve- ment in auditory skills in severe to profound hearingimpaired children between the ages 3 and 4. Regardless of their possession of appropriate hearing aids and access to other trainings such as speech and language therapy, it was revealed that, firstly, by conducting the auditory training method used in this study, all four levels of auditory skills in the hearing-impaired children improved; secondly, the Erber method was an appropriate and effective method for AT.

\section{Acknowledgment}

This work was supported by the Research Deputy of Iran University of Medical Science (Ethics Code Number: 369). Special thanks goes to the parents of hearing-impaired children.

\section{Conflict of Interest Statement}

Authors declared no conflict of interest.

\section{References}

Beier, L.O. et al, (2015). Auditory Training Benefits of the Hearing Aids Users: A Systematic Review. Rev. CEFAC. 17(4): 1327-1332.

Blamey, P.J., \& et al. (2001). Relationships among Speech Perception, Production, Language, Hearing Loss, and Age in Children with Impaired Hearing. Journal of Speech, Language, and Hearing Research, 44, 264-285. Bloom, J.L. (1980). The development of independent auditory training activities for severely and profoundly deaf student using audiological equipment. Am-Ann-Deaf, 125(6), 695-701.

Calderon, R. (2000). Parental Involvement in Deaf Children's Education Programs as a Predictor of Child's Language, Early Reading, and Social-Emotional Development. The Journal of Deaf studies and Deaf Education, 5(2), 140-155.

Clark TC. and Watkins, (1994 1985). THE SKI*1-11 MODEL: Programming for Hearing Impaired Infants through Home Intervention. SKI- HI Manual, SKI*HI Institute, Department of Communicative Disorders Utah State University, Logan, Utah.

Downs, M.P., \& Northern, J.L. (2014). Hearing in Chil- dren. Baltimore, USA: Williams and Wilkins.

Erber, N.P. (1982). Auditory Training. Washington DC, USA: GB Association for the Deaf.

Estabrooks, W. (1994). Auditory Verbal Therapy for Parents and Professions. Washington DC, USA: GB Association for the Deaf.

Hall, J.W. III. (2000). Handbook of Otoacoustic Emissions. San Diego, USA: Singular Publishing Group.

Henshaw, H. and Ferguson, M.A., (2015). Assessing the Benefits of Auditory Training to Real-World Listening: Identifying Appropriate and Sensitive Outcomes. www. researchgate.net/publication/257379085.

Hoekstra, C.C., Snik, A.F., Van den Borne, S., \& Van den Broek, P. (1999). Auditory Training in Severely and Profoundly Hearing -Impaired Toddlers: The Development of Auditory Skills. Int-J-Pediatr-otorhinolaryngol., 47(2), 201-4.

Itano, C.Y. Assessment and intervention with preschool children who are deaf and hard of hearing. Alpiner, J.G., \& McCarthy, P.A. editors. (2000). Rehabilitative Audiology. Baltimore, USA, Williams \& wilkins.

Jarollahi, F., (1388). A Practical Guide to Tavana Test: A Test for Auditory Skills Evaluation of 3-4 Years Old 
43. The Effects of Auditory Training by Erber Method...

Hearing-Impaired Children. Tehran, Iran: Pars Ketab.

Jarollahi, F., Modarresi, Y., \& Keyhani, M.R. (2010). Content validity of "Tavana" test: A test for evaluation of auditory skills of 3-4 year-old hearing-impaired Persian children. Audiology, 19(1), 11-22.

Kavanagh, D.J., (2017). Auditory Training in Speech Recognition and Hyperacuity. Open Access J. Neurol Neurosurg. 6(1).

Kricos, P.B. and McCarthy, P., (2007). From Ear to There: A Historical Perspective on Auditory Training. Seminars in Hearing. 28(2): 089-098.

Manouchehri, N., Ghahraman, M.A., Mobedshahi, F., Motesadi zarandi, M., \& Rovshan, B. (2011). Improvement of Speech Perception in Children with Cochlear Implant. Audiology, 20(2), 30-37.

Nerbornne, M.A., \& Show, R.L. (2002). Introduction to Audiologic Rehabilitation. Boston, USA: Allyn and Bacon.

Nicholas, J.G., \& Geers, A.E. (2006). Effects of Early Auditory Experience on the Spoken Language of Deaf Children at 3 Years of Age. Ear Hear, 27(3), 286-298.

Roeser, R.J., Valente, M., \& Hosford-Dunn, H. (2000). Audiology Diagnosis. NewYork, USA: Thieme.

Rohde, I. (1980). Auditory Training through Speaking
Directly into the ear. Scand-Audiol-Suppl., (Suppl. 10), 85-8.

Sininger, Y.S., Grimes, A., \& Christensen, E. (2010). Auditory Development in Early Amplified Children: Factors Influencing Auditory-Based Communication Outcomes in Children with Hearing Loss. Ear Hear, 31(2), 166-185.

Sirichokswad R. and et al.. Development of Auditory Training Program for Hearing-Impaired Children. http:// www.researchgate.net/publication/267295952. Nov 14, 2014.

Stout, G., \& Windel, J. (1986). The Developmental Approach to Successful Listening. San Diego, USA: Singular Publishing Group.

Tremblay, K., \& et al. (1997). Central auditory system plasticity: Generalization to novel stimuli following listening training. The Journal of Acoustical Society of America, 102, 762.

Tye-Murray, N. (2009). Foundations of Aural Rehabilitation. San Diego, USA: Singular Publishing Group. 


$$
\text { مقالة يزوهشى }
$$

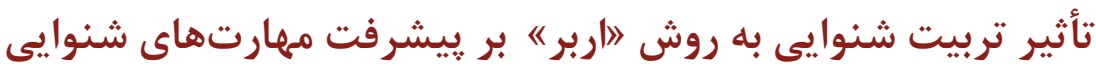

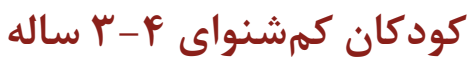

\section{فرنوش جار اللهى"'، افسانه علىنزاد كاشانى"، محمدرضا كيهانى '، عاطفه كمالوند"}

ا. عضو هيئتعلمى كروه شنوايىشناسى، دانشكدة علوم توانبخشى، دانشعاه علوم بزشكى ايران، تهران، ايران

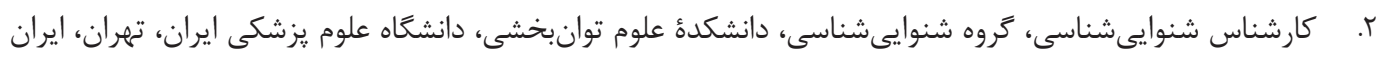

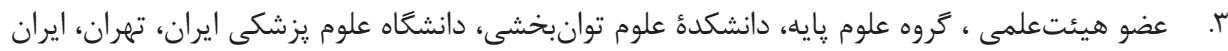

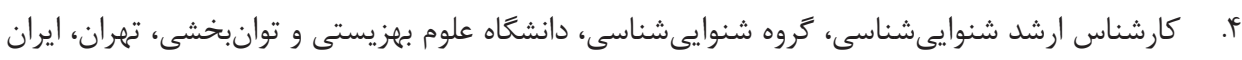

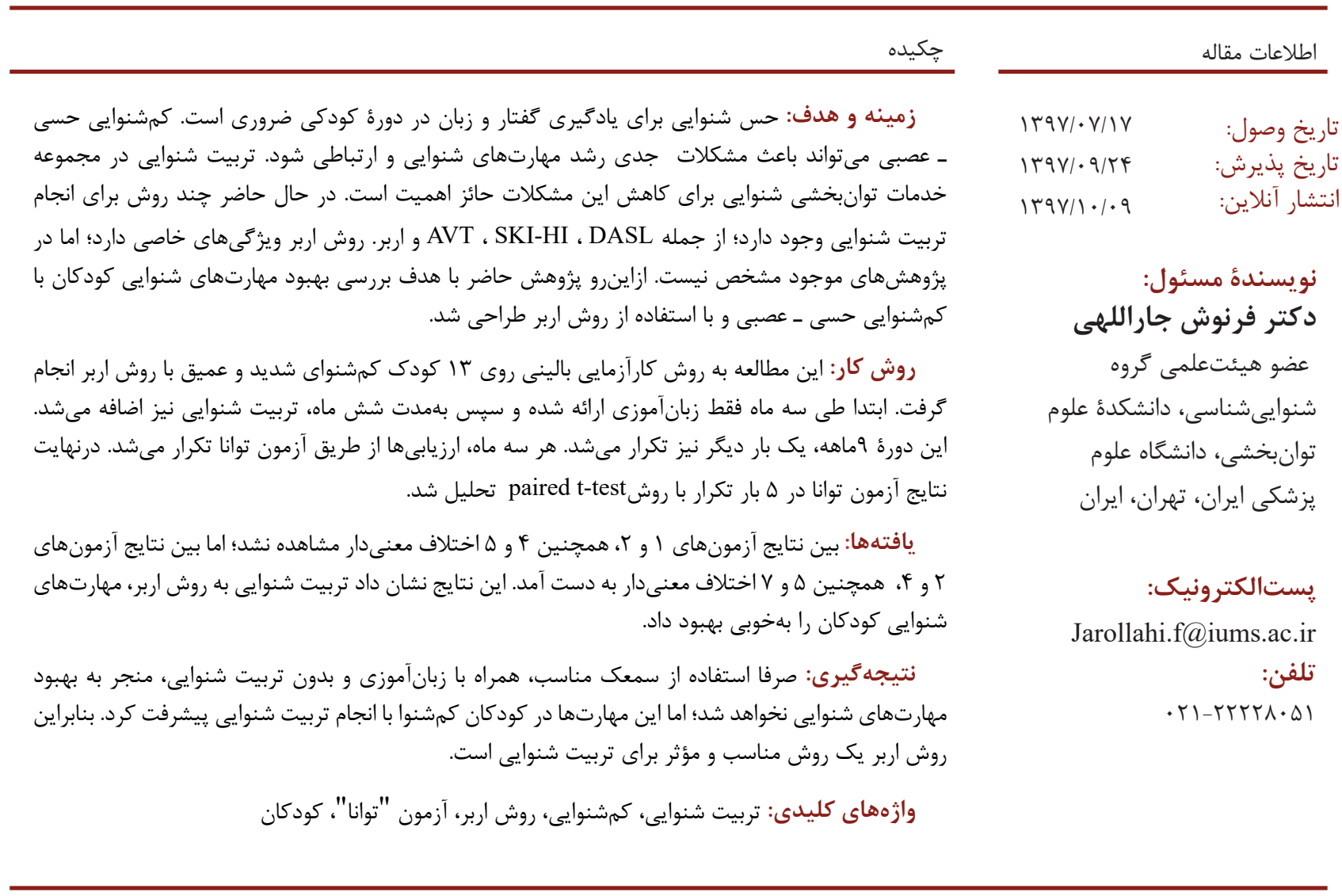

